\title{
A renovação das histórias em quadrinhos nas publicações alternativas brasileiras da década de $1980^{1}$ \\ The renewal of comics in brazilian alternative publications in the decade of 1980
}

\section{Roberto Elísio dos Santos}

Jornalista, com pós-doutorado em Comunicação pela Escola de Comunicação e Artes da Universidade de São Paulo - ECA/USP; professor da graduação e do Programa de Mestrado em Comunicação da Universidade Municipal de São Caetano do Sul - USCS; vicecoordenador do Observatório de Histórias em Quadrinhos da ECA/USP.

\section{Resumo}

Este trabalho apresenta um estudo da produção editorial alternativa de histórias em quadrinhos no Brasil na década de 1980. A pesquisa teve como objeto três pequenas editoras de São Paulo da época (Circo Editorial, Editora D-Arte e VHD-Diffusion), e objetivou analisar as publicações de quadrinhos dessas editoras, relacionando seu conteúdo com as transformações ocorridas no âmbito das narrativas sequenciais impressas e com a conjuntura política, econômica e cultural do País e do mundo.

Palavras-chave: histórias em quadrinhos, editoras, quadrinhos alternativos, década de 1980.

\begin{abstract}
This article presents a study of the alternative editorial production of comics in Brazil in the 80s. The researchfocusedthreesmallpublishingcompanies of that time (Circo Editorial, EditoraD-Arte e VHD-Diffusion) and intended to analyze the comics publications of thesepublishers and to relate its contents with the transformations in the field of sequentialgraphic narratives and with the political, economical and cultural conjuncture of the country and the world.
\end{abstract}

Keywords: comics, publishingcompanies, alternative comics, 1980's. 


\section{Introdução}

Refletindo as condições políticas verificadas no País no início da década de 1980, o mercado editorial de histórias em quadrinhos brasileiro ampliou-se, embora também tivesse sofrido com a crise inflacionária que assolou a economia. Ao lado de publicações periódicas de quadrinhos mainstream (comerciais) - de heróis (Marvel ou DC), protagonizados por personagens infantis (Mônica) ou oriundos do cinema de animação (Disney) - produzidas pelas grandes editoras, especialmente pela Abril e pela Globo, o público leitor encontrava nas bancas revistas que apresentavam histórias de humor ou de terror criadas por artistas brasileiros ou que traduziam material de vanguarda proveniente da Europa, da Argentina e dos Estados Unidos.

Pequenas editoras localizadas na capital paulista publicavam revistas impressas em papel de baixa qualidade, que abrigavam em suas páginas quadrinhos reproduzidos, na maior parte das vezes, em preto em branco, o que diminuía os custos. A periodicidade, mensal ou bimestral, nem sempre era cumprida. Em contraposição às revistas comerciais, essas publicações podem ser denominadas como "alternativas", termo que o crítico teatral Edelcio Mostaço (1984: 4-5) considerou que, como outros conceitos (independente, marginal ou experimental), "qualificam, com maior ou menor rigor, atitudes ou gestos evidenciados em suas atuações; e representam (...) fases; devendo-se empregá-los - para não sucumbir imediatamente ao Poder - com parcimônia". O termo "alternativo", portanto, pode se referir a uma postura política de contestação ou de resistência à visão dominante, a uma inovação artística ou a mais uma opção para o público (ou segmento de público) dentro do mercado.

Mas as narrativas gráficas sequenciais presentes nas páginas dessas publicações contribuíram para a renovação da história em quadrinhos naquele período, como será mostrado nesse trabalho. Além de inovações estéticas e narrativas, essas $\mathrm{HQs}$ levavam temas de relevância no momento (o acirramento da Guerra Fria, a possibilidade de um conflito nuclear, o consumismo e o individualismo em ascensão nos centros urbanos, sexo e violência, dentre outros).

Das várias casas publicadoras surgidas nos anos 1980, três delas tornaram-se objeto de estudo desta pesquisa: Circo Editorial, D-Arte e VHD-Diffusion. Ao longo do trabaIho desenvolvido, foram realizadas entrevistas em profundidade com editores e artistas. Simultaneamente, a pesquisa documental buscou reunir o acervo produzido por essas editoras. O material coletado foi digitalizado (capas de cada edição) e indexado (por data de publicação, título da história, autor(es), número de páginas e outros dados) ${ }^{1}$ para possibilitar a análise, que privilegiou a relação entre esse produto cultural midiático e a conjuntura política e econômica na qual foi elaborado, seguindo a proposição de Kellner (2001: 143):

Devido à proximidade que mantêm com as condições sociais em que surgiram, os textos populares da mídia constituem um acesso privilegiado às realidades sociais de sua era: assim, a sua interpretação possibilita a compreensão daquilo que está de fato acontecendo em determinada sociedade em dado momento.

\section{Década de 1980: entre crises e transformações}

Paradoxalmente, a década de 1980 foi um momento histórico pautado, por um lado, pela redemocratização de sociedades que viveram décadas sob regimes ditatoriais (Espanha, Brasil e Argentina) e, por outro, pelo fortalecimento de governos conservadores (Inglaterra e Estados Unidos). O acirramento da Guerra Fria entre os blocos capitalista e socialista mais o crescimento da corrida armamentista aumentavam a possibilidade de um confronto nuclear capaz de dizimar grande parte da vida no planeta.

A abertura democrática no Brasil possibilitou maior liberdade de expressão tanto no âmbito da imprensa como no da cultura. Movimentos que encampavam reivindicações da população, a exemplo da campanha das "Diretas-Já", que exigia a eleição direta para a presidência da República após duas décadas de regime militar, ganharam as ruas. $\mathrm{O}$ abrandamento da censura possibilitou o acesso a obras literárias (Dentes ao sol, de Ignácio de Loyola Brandão), musicais ("Para não dizer que não falei das flores", de Geraldo Vandré), teatrais (Rasga coração, de Oduvaldo Vianna Filho) e cinematográficas ( $Z$, de Costa-Gavras, Laranja mecânica, de Stanley Kubrick, e $O$ último tango em Paris, de Bernardo Bertolucci, dentre outros exemplos) que se encontravam proibidas há anos.

Os centros urbanos, como é o caso da cidade de São Paulo, acolheram naquela época a emergência de uma cultura jovem alternativa. Proposta política e estética, a atitude alternativa ou independente contrapunha-se aos parâmetros comerciais da indústria cultural e à submissão dos produtores às verbas do Estado, destinadas ao setor cultural. Representavam essa iniciativa o Grupo de Teatro Ornitorrinco, o espaço Lira Paulistana - que se tornaria

\footnotetext{
${ }^{1}$ Os dados coletados e indexados encontram-se disponíveis para consulta no site do Observatório de Histórias em Quadrinhos da ECA/USP.
} 
A renovação das histórias em quadrinhos nas publicações alternativas brasileiras da década de $\mathbf{1 9 8 0}$

um selo fonográfico responsável por discos de Arrigo Barnabé e Itamar Assumpção -, as produtoras de cinema instaladas na Vila Madalena e as editoras de histórias em quadrinhos (Editora D-Arte, Circo Editorial, Press Editorial, Vidente, VHD-Diffusion etc.).

Do ponto de vista econômico, a implantação do modelo neoliberal levou à ascensão do capital especulativo, enquanto direitos trabalhistas eram eliminados em um mercado que se regulava com a presença menor do Estado, aumentando os ganhos da elite e, ao mesmo tempo, gerando desemprego. Países do Terceiro Mundo sofriam com os juros cobrados sobre suas dívidas externas, como foi o caso do Brasil, que enfrentou, também, uma forte crise inflacionária, cujas consequências foram a troca da moeda, o desabastecimento e a distância entre as classes sociais, com o decréscimo do poder aquisitivo dos mais pobres.

O aumento do desemprego e a diminuição do amparo estatal contribuíram para o crescimento da violência nos grandes centros urbanos. Ao mesmo tempo, o risco de epidemias de novas doenças, como Aids e a febre hemorrágica provocada pelo vírus ebola, tornavam-se ameaças para o convívio social, resultando em atitudes individualistas. O sociólogo Christopher Lasch (1986: 10-12), ao tratar do individualismo nesse contexto, considerou que o 'risco de desintegração individual estimula um sentido de individualidade que não é "soberano" ou 'narcisista', mas simplesmente sitiado". E salientou:

O eu mínimo narcisista é, antes de tudo, um eu inseguro de seus próprios limites, que ora almeja reconstruir o mundo à sua própria imagem, ora anseia fundir-se em seu ambiente numa extasiada união.

No que concerne às ideias, naquele momento, a visão teórica predominante era de que, principalmente no campo das artes e das comunicações, a sociedade ocidental chegara a uma nova fase histórica, a pós-modernidade, que sucedera à modernidade, cujas perspectivas teriam se esgotado. Embora autores como Habermas (1983: 8691) rejeitem essa ruptura, por crer que o projeto de modernidade ainda não tenha se cumprido, o termo "pósmoderno" passou a caracterizar a produção cultural dos anos 1980.

Kellner (2001: 69-73) advertiu que "não há um discurso de consenso em torno do pós-moderno, mas, ao contrário, uma série de paradigmas e discursos em disputa. Para ele, o discurso sobre o pós-moderno é um construto cultural e teórico". O mundo vive, em sua opinião, "entre uma era moderna em envelhecimento e uma nova era pós-moderna que ainda precisa ser adequadamente conceituada". A respeito dessas divergências, Connor (1993:25) afir- mou que já não pode "ser possível negar que o pós-modernismo existe, visto que o debate crítico sobre ele pode ser visto, em parte, como a prova de sua existência".

Entre as características que marcam a postura pós-moderna, especialmente nas artes, encontram-se o uso de metaficção, o niilismo (resultado da frustração com os ideais revolucionários das décadas de 1960 e 1970, que não se concretizaram), o pastiche (mistura de estilos), a nostalgia (olhar saudoso para um passado recente mais ingênuo) e a presença cada vez maior de simulacros (signos que se tornam independentes de seus referentes). É possível identificar esses elementos em diversos produtos culturais midiáticos, do cinema (filmes como Blade Runner, de Ridley Scott, Dublê de corpo, de Brian De Palma ou $A$ Dama do Cine Shangai, de Guilherme de Almeida Prado) e da TV, passando pela literatura e pela música.

Em relação às histórias em quadrinhos, Scolari (1999: 316) considerou que as mudanças sofridas pelas narrativas gráficas sequenciais na virada dos anos 1970 para os 1980 refletem, em sua essência, a visão chamada de pós-moderna que passou a nortear a criação artística e a crítica naquele momento. Para esse autor, as temáticas das histórias

(...) - como a violência urbana e o sexo desenfreado filtrado por uma persiana - podem ser englobadas no (desgastado) conceito de "pós-modernismo". A colagem de linguagens e o cross-over textual são também claras atitudes pós-modernas que apareceram nos quadrinhos dos anos 1980.

Pela ruptura pós-moderna, torna-se possível perceber, nos quadrinhos dos anos 1980, referências a estilos gráficos consagrados, como a linha clara, citações da estética e da narrativa noir (iluminação expressionista e narração em primeira pessoa centrada no protagonista masculino, que resolve os conflitos usando os punhos ou armas de fogo), alusões à publicidade, ao cinema, à literatura e aos próprios quadrinhos. Também se nota a mistura de desenhos (realistas e caricaturais), pinturas e fotos. A arte "retro" usada para retratar os temas do momento (Guerra Fria, holocausto nuclear, violência urbana, esgotamento das ideias) promoveu um distanciamento propício para a reflexão. A fragmentação e a multiplicação do foco narrativo e a recusa do maniqueísmo tornaram-se outras características das histórias.

\section{Quadrinhos e inovações nos anos $\mathbf{1 9 8 0}$}

Ao longo da década de 1980, surgiram novos estilos e temáticas que modificaram as histórias em quadrinhos, orientando-as para um público adulto e sofisticado. Essas inovações já estavam em curso desde os anos 1960, quan- 
do surgiu o comix underground norte-americano ${ }^{2}$. No caso da Banda Desenhada francesa, a renovação foi reflexo das manifestações de maio de 1968, que também influenciaram outras formas de arte, como o cinema e o pensamento acadêmico.

Em 1972, artistas que integravam a revista Pilote, como Gotlib e Mandryka, romperam com esse periódico e lançaram o título L'Echo des Savanes, que publicava quadrinhos de humor com uma postura mais radical. Três anos depois, os quadrinistas Moebius (pseudônimo de Jean Giraud) e Druillet formaram o grupo Les Humanoïdes Associés e criaram a revista Metal Hurlant. Editada até 1987, trazia em suas páginas quadrinhos autorais de fantasia e ficção científica. Mesclando o estilo da linha clara - tradicionais na produção franco-belga - com hachuras, as histórias mostravam cidades futurísticas sujas e planetas desérticos hostis, tendo como protagonistas personagens sem o perfil do herói tradicional. Mas, apesar do sucesso editorial - havia edições em vários países europeus e nos Estados Unidos, onde recebeu o título Heavy Metal, que continua a ser publicado - e da influência que teve em artistas de vários países, a Metal Hurlant não conseguiu sobreviver aos anos 1980. Esse período foi marcado pelo desaparecimento das revistas periódicas de quadrinhos na França, substituídas por álbuns de quadrinhos vendidos em livrarias.
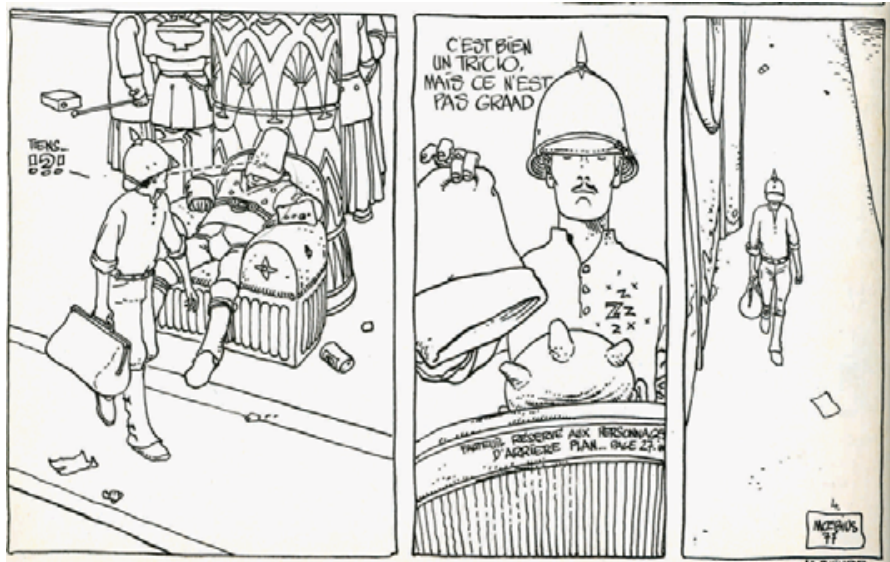

Figura 1: A ficção científica fora dos padrões estabelecidos, no traço de Moebius

2 O comix underground norte-americano surgiu no bojo da contracultura (movimento artístico que se opõe aos produtos comerciais da indústria cultural, como o cinema, a música e os quadrinhos) e das manifestações contrárias à Guerra do Vietnã e à discriminação racial nos Estados Unidos. Os principais quadrinistas foram Robert Crumb (criador dos personagens Fritz The Cat e Mister Natural) e Gilbert Shelton (autor das histórias protagonizadas pelos Freak Brothers), que falavam de sexo e drogas e contra a sociedade. Sobre esse assunto, ver o livro Rebel visions (Fantagraphics Books, 2002), escrito por Patrick Rosenkrantz.
De acordo com Scolari (1999: 70), se Les Humanoïdes "descendem das barricadas de maio de 1968", o marco histórico político e cultural para os italianos aconteceu em 1977, na cidade de Bolonha. A consequência do "movimento de 77" no fumetto italiano foi a criação do Grupo Valvoline, cujas primeiras produções apareceram na revista Alter Alter, para a qual criaram o suplemento ValvolineMotorcomics.

Outra revista de quadrinhos de importância na Itália foi Frigidaire, que publicava também textos políticos, contos, fotonovelas eróticas, entrevistas etc. No que se refere às narrativas sequenciais gráficas, nesse título foram editadas as histórias humorísticas, repletas de sexo e violência, realizadas por Massimo Mattioli, e as aventuras do androide Ranxerox, criado por Stefano Tamburini. Ao longo da década de 1980, além do quadrinho alternativo e autoral, o fumetto caracterizou-se por histórias de terror, sendo a estrela principal do gênero o detetive do sobrenatural Dylan Dog, personagem publicado pela Editora Sergio Bonelli, cujo sucesso levou à criação de diversos periódicos dedicados aos quadrinhos do estilo splatter (sangue e tripas), como Splatter, Gore-Scanners, Holocaust e Horrorfest, dentre outros.

Até meados da década de 1970, o quadrinho alternativo na Espanha circulava clandestinamente na forma de fanzines. Mas o fim da ditadura franquista, em 1976, assinalou um período de revigoramento da produção artística espanhola, inclusive das histórias em quadrinhos. A esse respeito, Dopico (2005: 135-136) afirmou:

A transição política também afetou o mundo dos quadrinhos. Com o desaparecimento do franquismo e o relaxamento da censura, têm início de verdade, pela primeira vez na história do quadrinho espanhol, a aparição e o desenvolvimento de histórias adultas na forma e no conteúdo.

No início dos anos 1980, a Espanha viveu um período de renascimento cultural: em Barcelona, por exemplo, o cineasta Pedro Almodóvar dava início à sua carreira, renovando o cinema espanhol, enquanto o arquiteto Josep Maria Berenguer lançava a revista de quadrinhos El Víbora, que contava com o apoio econômico do editor Josep Toutain. Essa publicação, segundo Dopico (2005: 320), "surgiu de forma espontânea, devido à ebulição da sociedade, e apresentava em suas páginas quadrinhos de ação, humor, sexo, violência, ternura, miséria, amor e morte".

Além de trabalhos produzidos por artistas de outros países (Yoshiro Tatsumi, Kim Deitch, Art Spiegelman, Basil Wolverton etc.), El Víbora reuniu talentos espanhóis como Nazário Luque Vera, Francesc Capdevila Gisbert (mais conhecido como Max) e Daniel Torres, dentre outros. Da 


\section{A renovação das histórias em quadrinhos nas publicações alternativas brasileiras da década de 1980}
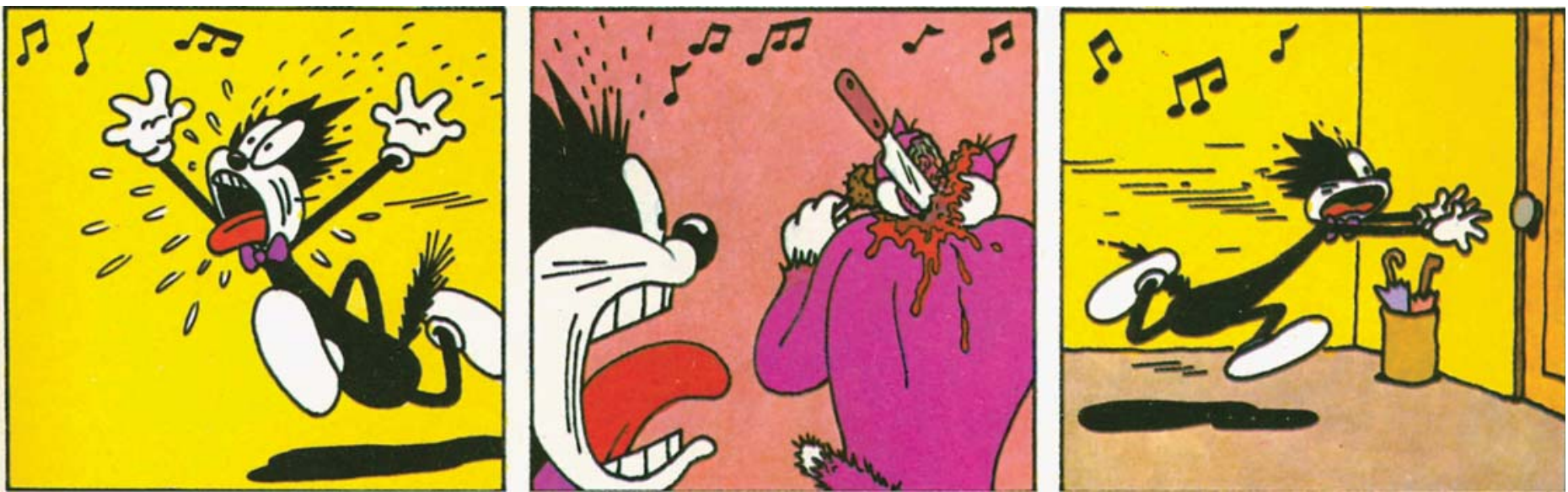

Figura 2: Squeak The Mouse, de Mattioli: sexo e violência com desenhos infantis

imaginação desses artistas surgiram narrativas pouco convencionais: Nazário criou a história Anarcoma, protagonizada por um detetive travesti; depois de fazer as aventuras de Gustavo, personagem antropomórfico que se opunha à opressão da sociedade, Max deu vida a Peter Pank, que misturava o desenho animado de Walt Disney ao movimento punk, em histórias violentas e eróticas; o estilo retrô de Torres remetia aos quadrinhos de linha clara feitos por Hergé e às peças publicitárias dos anos 1940 (seja no design de automóveis, mobília e prédios, seja no que concerne a penteados e figurinos), mas as histórias eram repletas de ironia e ambientadas em cenários futuristas, a exemplo de Triton.

Três artistas espanhóis que também se destacaram naquele momento foram Carlos Muñoz, Miguel Angel Prado e Antonio Martín. O primeiro, veterano que passou a infância em um orfanato, realizava histórias que denunciavam a ditadura franquista e a luta de classes em uma sociedade marcada pela desigualdade social, como na autobiografia Parracuellos. Mais conhecido como Miquelanxo Prado, o segundo artista espanhol citado começou fazendo quadrinhos de ficção científica para, depois, concentrar-se em narrativas que abordavam, de maneira kafkiana, os absurdos do cotidiano. Do ponto de vista formal, na opinião de De Santis (2004: 113), Prado "é um dos autores que mais experimentou com a linha e a cor". Jaime Martín, por sua vez, realizou a história Sangre de barrio (que, no Brasil, recebeu os títulos Sangue de bairro e Vida louca), que acompanha a trajetória de personagens marginais que habitam um subúrbio pobre e violento de Barcelona. Merecem destaque, ainda, os trabalhos da dupla Enrique Sanchez Abuli e Jordi Bernet, como Torpedo 1936, história de gângster ambientada nos Estados Unidos durante a Depressão Econômica.

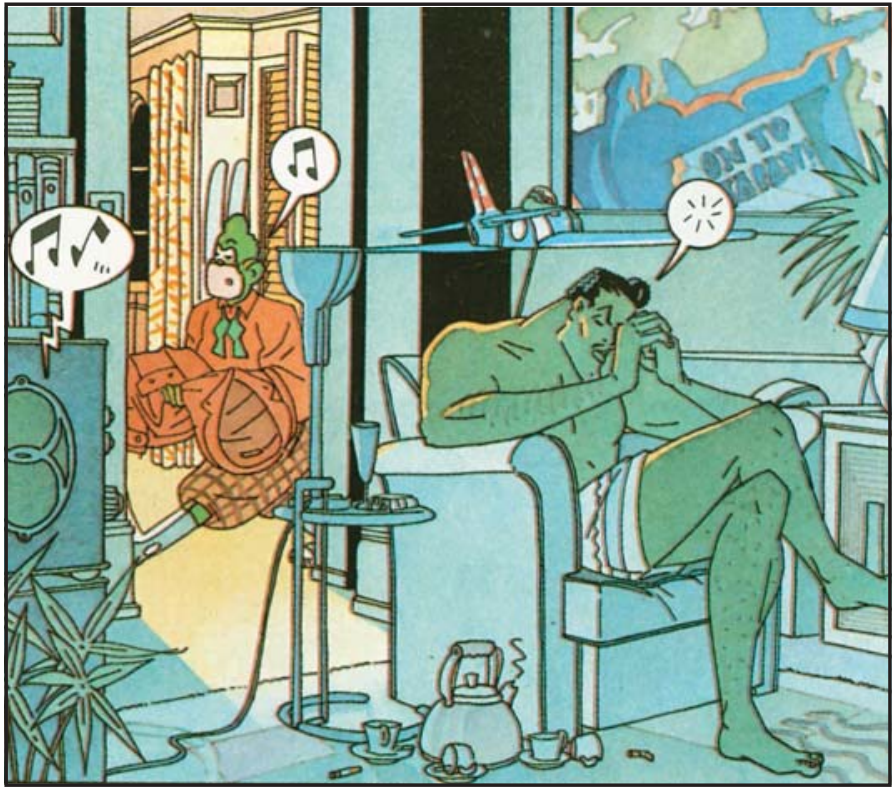

Figura 3: Desenho de Daniel Torres: estética retrô em ambiente futurista

Outro país de língua hispânica que se beneficiou do final do regime de exceção a que era submetido foi a Argentina. Lá, a principal publicação alternativa de quadrinhos foi a revista Fierro (cujo subtítulo, Historietas para sobrevivientes, remetia aos que conseguiram escapar ilesos à ditadura militar), dirigida por Juan Sasturain, que promoveu, no entender de De Santis (2004: 116-117), "uma revolução gráfica e textual", que apresentava em suas páginas textos sobre política, história, literatura, cinema e quadrinhos. Oferecia aos leitores trabalhos de Moebius, Crumb e de artistas argentinos, como Carlos Trillo, Guillermo Saccomanno, Alberto e Henrique Breccia, Do- 
mingo Mandrafina, Fontanarrosa, Juan Gimenez, Horacio Altuna e Francisco Solano López, dentre outros. Também debutaram nessa publicação novos talentos, a exemplo de Max Cachimba (pseudônimo de Juan Pablo González). Ainda segundo De Santis, essa revista "acabou por cobrir o vazio que havia deixado a recém-terminada ditadura". A esse respeito, Merino (2003: 263) afirmou:

A revista Fierro, que apareceu em 1984, é fundamental neste novo período de democracia e se caracteriza por ter um tom vanguardista e inovador. $\mathrm{A}$ influência do quadrinho underground norte-americano e europeu se faz latente, sobretudo, no suplemento que acompanha a revista Fierro a partir de 1985.

Se a Espanha e a Argentina viviam um período de redemocratização, na Inglaterra tinha início, no final da década de 1970, a volta do conservadorismo ao poder, com a eleição de Margaret Thatcher para o cargo de primeiro-ministro. A política neoliberal implantada pelo governo gerou desemprego e protestos. Paralelamente, o movimento punk atraía os jovens que se sentiam sem esperança. Nesse clima de revolta, surgiram publicações comerciais de quadrinhos com enfoque radical: Viz, Action e 2000 $A D$, sendo as duas últimas dirigidas por Pat Mills.

Lançada em 1977, 2000 AD introduziu, a partir do segundo número, as histórias do violento Judge Dredd, personagem produzido por Mills, John Wagner, Carlos Ezquerra e Brian Bolland. Policial, juiz e executor, Dredd faz parte da força policial repressora de uma megacidade norte-americana em um futuro pós-apocalíptico, que vive sob toque de recolher. De acordo com Scolari (1999: 131), uma prática comum da revista era transportar "para cenários futurísticos os problemas cotidianos da sociedade britânica". Quanto à ambientação das histórias ser nos Estados Unidos, How (2000: 227-228) considerou que a revista tratou da relação entre Inglaterra e Estados Unidos "não por meio de ironia direta; mas, ao contrário, pela tática pósmoderna da 'cumplicidade crítica' com a cultura mainstream norte-americana, especialmente o cinema de Hollywood".

Nos Estados Unidos, o mercado editorial de histórias em quadrinhos comerciais vivia, no começo dos anos 1980, uma retração. Mas a proliferação de graphic novels - publicações de quadrinhos voltadas para o público adulto que apresentavam inovações gráficas, narrativas e temáticas - impulsionou a venda de histórias em quadrinhos com a formação de um novo público e o resgate de antigos leitores. Popularizado pelo veterano Will Eisner a partir da publicação do livro de quadrinhos Um contrato com Deus, o termo "romance gráfico" foi empregado para designar produções autorais (mesmo que muitas obras fossem realizadas por editoras comerciais) vendidas em livrarias. A esse

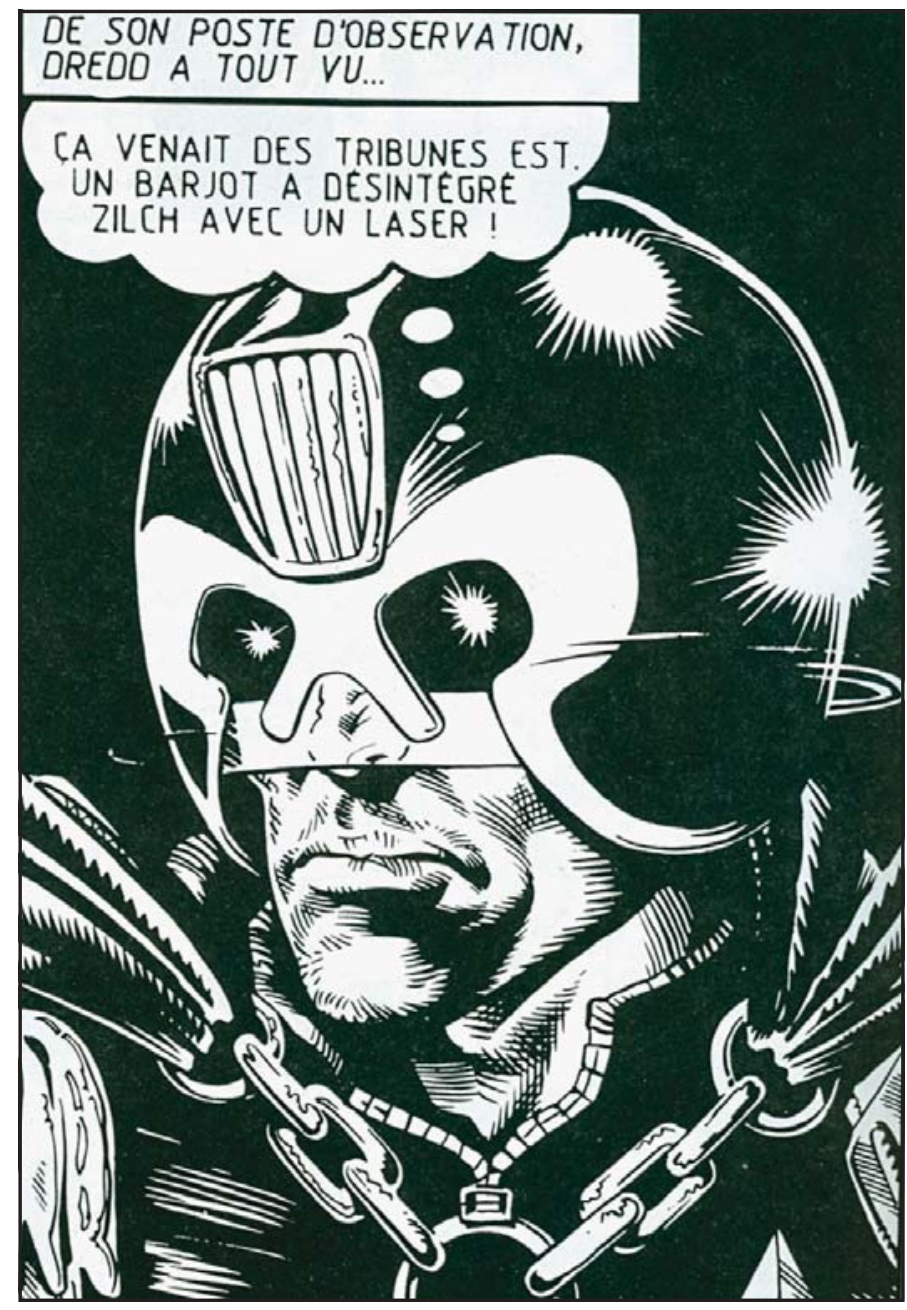

Figura 4: Violência urbana e autoritarismo são as tônicas das histórias de Judge Dredd

respeito, Weiner (2003: 21-22) afirmou que a obra de Eisner "foi o primeiro trabalho artístico original de quadrinhos publicado por uma tradicional editora de livros norte-americana", embora, desde a década de 1930, coletâneas de histórias em quadrinhos tenham sido editadas no formato de livros. E o referido autor acrescentou que os quadrinhos no formato de livro editados por editoras conceituadas ganharam a confiança de um público geral.

Destacaram-se, nos anos 1980, os trabalhos realizados por Frank Miller (Batman - O cavaleiro das trevas, Elektra assassina, Ronin) e Alan Moore (A piada mortal, $V$ de vingança, Watchmen). Conectadas ao seu momento histórico, essas graphic novels abordavam temas como a Guerra Fria, a violência urbana, a possibilidade de um conflito nuclear e a ascensão de governos conservadores e repressores, dentre outros assuntos. Do ponto de vista da narrativa, multiplicaram-se os focos narrativos e, no que 
A renovação das histórias em quadrinhos nas publicações alternativas brasileiras da década de $\mathbf{1 9 8 0}$

concerne à arte, utilizava-se o procedimento pós-moderno de mistura de estilos. O artista Bill Sienkiewicz (realizador da graphic novel Stray toasters), por exemplo, empregou na mesma história imagens caricaturais e realistas, utilizando técnicas como o desenho, a pintura e a colagem.

\section{Editoras e publicações brasileiras dos anos 1980}

As grandes editoras brasileiras (principalmente Abril e Globo), embora também publicassem esporadicamente graphic novels e minisséries mais autorais, tinham como principal produto o quadrinho mainstream ${ }^{3}$ norte-americano (Disney, heróis da Marvel e da DC Comics), além de revistas infantis feitas por autores nacionais, sendo Mauricio de Sousa o mais popular. Mas pequenas editoras, a maioria delas sediada em São Paulo, passaram a oferecer aos leitores revistas que apresentavam as tendências mais recentes dos quadrinhos europeus e trabalhos de autores underground americanos, e abriam suas páginas para quadrinistas brasileiros já conhecidos pelo público ou que estavam começando suas carreiras artísticas.

\section{A) Circo Editorial}

Idealizada e implantada pelo editor Antonio de Souza Mendes Neto, conhecido como Toninho Mendes, a Circo Editorial iniciou oficialmente suas atividades em 26 de abril de 1984 (dia em que o Congresso Nacional rejeitou a emenda que instituía a eleição direta para presidente da República) com o lançamento do primeiro álbum da Série Traço e Riso: uma compilação de tiras de quadrinhos Chiclete com Banana, realizadas pelo cartunista Angeli.

Ao longo de 11 anos de atividade, a Circo Editorial foi responsável pelo lançamento de várias publicações de histórias em quadrinhos, a maior parte de humor. A revista CirCo, que chegou às bancas em outubro de 1986, era editada por Luiz Gê e apresentava trabalhos de quadrinistas europeus de destaque na época (Moebius, Abuli e Bernet, Liberatore, Dionnet e Frank Margerin, dentre outros) e norteamericanos (a exemplo de Robert Crumb), além de artistas brasileiros (Luiz Ge, Laerte, Glauco etc.).

Um dos títulos de maior sucesso da Circo Editorial foi a revista Chiclete com Banana, que trazia tiras e histórias

${ }^{3}$ Em oposição do quadrinho autoral underground ou independente, a produção mainstream ou comercial caracteriza-se por uma produção em série e pela divisão do trabalho entre vários profissionais (roteirista, desenhista, arte-finalista, letreirista, colorista e editor, dentre outros), que produzem histórias com personagens pertencentes às editoras e que já se tornaram ícones da cultura midiática.
Tabela 1: Publicações da Circo Editorial

\begin{tabular}{|c|c|c|c|}
\hline Título & $\begin{array}{l}\text { Data } \\
\text { inicial }\end{array}$ & $\begin{array}{l}\text { Data } \\
\text { final }\end{array}$ & $\begin{array}{c}\text { Número } \\
\text { de edições }\end{array}$ \\
\hline Circo & 1986 & 1988 & 8 \\
\hline Circo Especial & 1988 & 1988 & 1 \\
\hline Piratas do Tietê & 1990 & 1992 & 14 \\
\hline Striptiras & 1993 & 1994 & 15 \\
\hline Geraldão & 1987 & 1991 & 18 \\
\hline Geraldão segunda dentição & 1991 & 1994 & 11 \\
\hline Geraldão 90 cm & 1993 & 1994 & 2 \\
\hline Geraldão Especial & 1990 & 1990 & 1 \\
\hline Lúcifer & 1994 & 1995 & 2 \\
\hline Big Bang Bang & 1994 & 1994 & 4 \\
\hline Níquel Náusea & 1988 & 1990 & 10 \\
\hline Chiclete com Banana & 1985 & 1990 & 24 \\
\hline Chiclete Remix & 1988 & 1988 & 1 \\
\hline Chiclete - Série Tipinhos Inúteis & 1991 & 1994 & 10 \\
\hline Chiclete com Banana Especial & 1987 & 1994 & 4 \\
\hline Chiclete Especial Lovestórias & 1987 & 1987 & 1 \\
\hline $\begin{array}{l}\text { Chiclete com Banana } \\
\text { (Circo/Brasiliense) }\end{array}$ & & & 1 \\
\hline The Best of Chiclete & 1995 & 1995 & 3 \\
\hline $\begin{array}{l}\text { Rê Bordosa - Memórias de } \\
\text { uma Porralouca }\end{array}$ & 1995 & 1995 & 1 \\
\hline $\begin{array}{l}\text { FHC Biografia não autorizada } \\
\text { - Angeli (álbum) }\end{array}$ & 1995 & 1995 & 1 \\
\hline Los 3 Amigos Especial & 1989 & 1989 & 1 \\
\hline Los 3 Amigos (Circo/Ensaio) & 1992 & 1994 & 2 \\
\hline Série Traço e Riso & 1984 & 1986 & 12 \\
\hline Coleção Circo & 1991 & 1991 & 6 \\
\hline $\begin{array}{l}\text { Gato e Gata - Tiras de Laerte } \\
\text { (álbum) - Circo/Ensaio }\end{array}$ & 1995 & 1995 & 1 \\
\hline $\begin{array}{l}\text { As espoucadas de Geraldão } \\
\text { (álbum) -Circo/Ensaio }\end{array}$ & 1995 & 1995 & 1 \\
\hline $\begin{array}{l}\text { Circo Quadrinhos Pôster - } \\
\text { Laerte (Circo/Sampa) }\end{array}$ & 1987 & 1987 & 1 \\
\hline Revista Pôster Os Skrotinhos & 1994 & 1994 & 1 \\
\hline Total de edições & & 157 & \\
\hline
\end{tabular}

realizadas por Angeli. Se, na década de 1970, o humor gráfico brasileiro voltava-se para a política, devido ao regime de exceção vigente, nos anos 1980, com a redemocratização, a sátira ao comportamento da classe média urbana passou a predominar. Marcelo Coelho (BRYAN, 2004: 18) asseverou que a geração dos anos 1980, 


\section{A renovação das histórias em quadrinhos nas publicações alternativas brasileiras da década de 1980}

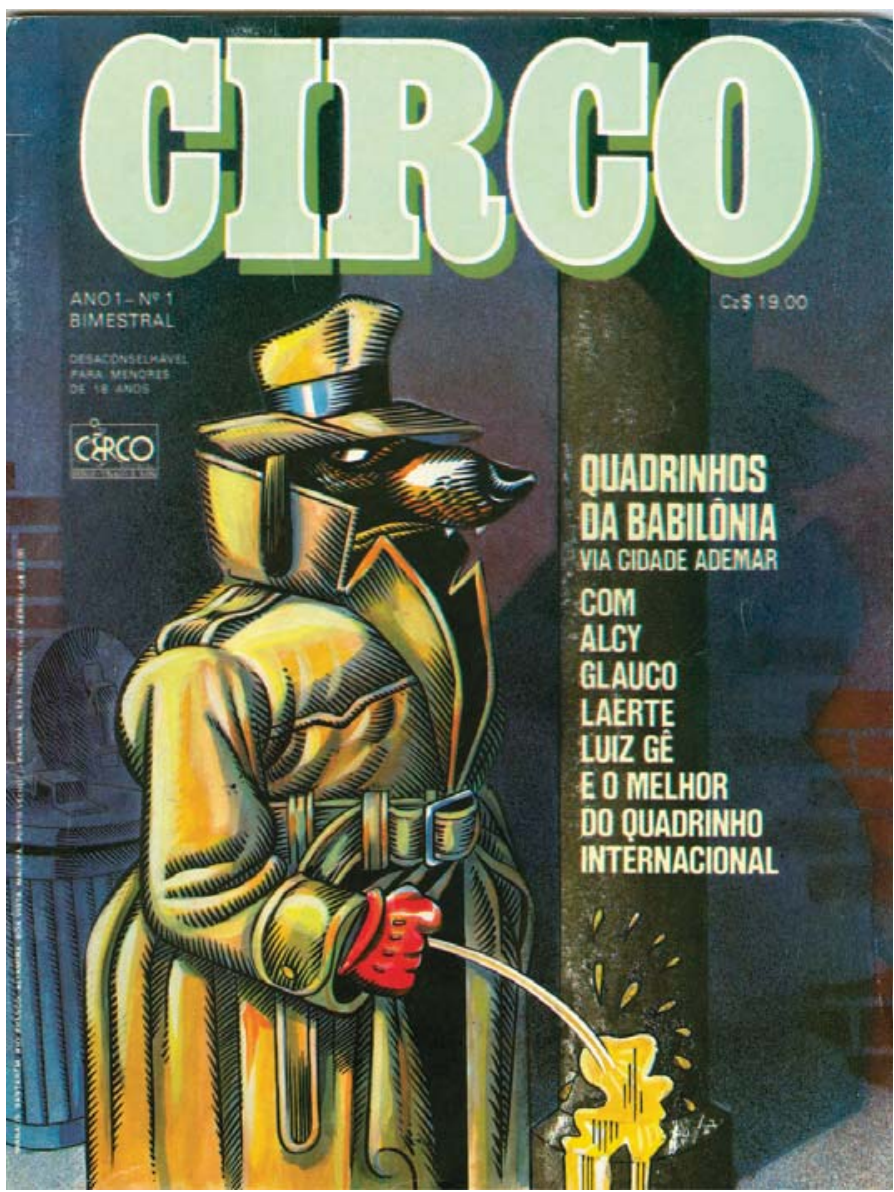

Figura 5: Capa da primeira edição da revista Circo, concebida por Luiz Gê

crescida durante a ditadura, não era despolitizada, mas soube abrir-se "para questões que não constavam do programa da esquerda tradicional". Para esse autor, "o surgimento de um espírito humorístico, desconchavado, celebratório, num ambiente ainda coberto de pessimismo e amargura, não são características tão 'despolitizadas' assim".

Nesse sentido, os personagens de Angeli apontam para os impasses e contradições surgidas naquele momento histórico. É o caso de Meiaoito, o antigo militante de esquerda que vive de recordações do passado e não consegue se adaptar aos novos tempos nem conquistar sua paixão, Rita Pop. Seu único seguidor, o homossexual Nanico, está mais interessado em sexo do que em fazer a revolução. Na concepção de Nadilson Manoel da Silva (2002: 96), esse personagem é reprimido sexualmente: "Os quadrinhos de Meiaoito, apesar de serem predominantemente relacionados à política, possuem em suas entrelinhas uma temática sexual".
Deslocados também são os velhos hippies Wood e Stock, agora gordos e calvos, e Bibelô, o último dos machistas. O punk Bob Cuspe está em conflito permanente com a sociedade. Já os Skrotinhos desconstroem, com suas tiradas sarcásticas, a pose dos intelectuais e artistas, os adeptos dos modismos, a arrogância dos machistas e as ideias feministas. As mulheres conquistaram a autonomia com o movimento feminista, mas não conseguem lidar com a solidão e a nova forma de relação com os homens, como é o caso de Rê Bordosa e Mara Tara. Sobre a primeira, Nery (2006: 58) afirmou:

Rê Bordosa tem uma visão da sociedade de seu tempo como algo decadente e coloca suas atitudes em um universo muito restrito, não indicando comportamento semelhante a outras pessoas; não se reconhece como estereótipo forjado no interior da sociedade que nega. Ela mesma aborda questões fundamentais ao status quo - casamento, integração às normas - como positivo, mas não para ela.

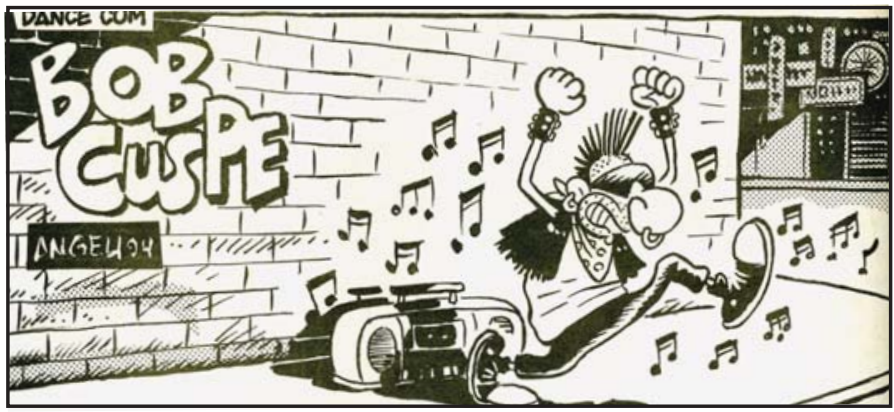

Figura 6: Bob Cuspe representa a cultura urbana e a rebeldia

O cartunista Laerte publicou, pela Circo Editorial, as revistas Piratas do Tietê e Striptiras. Na primeira, ao lado dos anárquicos bucaneiros que navegam pelo Rio Tietê, foram editadas histórias escritas pelo roteirista norte-americano Harvey Pekar e desenhadas por Robert Crumb. Já a segunda reunia tiras e histórias com diversos personagens de Laerte, como o Zelador; o Síndico; Gato e Gata; Fagundes, o Puxa-Saco; o Grafiteiro. As narrativas ambientadas em um condomínio, além de retratar o cotidiano de um típico espaço urbano, serviam como metáfora de um país cuja elite se refugia em prédios cercados por hordas de miseráveis. Habitantes como o autoritário Síndico e o severo e conservador Capitão Douglas (militar aposentado, mas sempre alerta) fazem alusão à ditadura militar que havia terminado há pouco.

As tiras e histórias com os personagens criados pelo cartunista Glauco, especialmente o solteirão consumista 
A renovação das histórias em quadrinhos nas publicações alternativas brasileiras da década de $\mathbf{1 9 8 0}$

Geraldão (que vive uma relação edipiana com sua mãe), a carente Dona Marta e o moderno e briguento Casal Neuras saíram nas revistas Geraldão, Geraldão Segunda Dentição e Geraldão $90 \mathrm{~cm}$. Juntos, Glauco, Laerte e Angeli desenvolveram as narrativas de Los 3 Amigos, em que os próprios artistas são mostrados como bandoleiros mexicanos. Outro quadrinista que publicou seus trabalhos (os caubóis gays Rock \& Hudson e a Família Bíceps, dentre outros) pela Circo Editorial, na revista Big Bang Bang, foi o gaúcho Adão Iturrusgarai, que se tornou o "quarto amigo".

\section{B) Editora D-Arte}

Com a censura aos quadrinhos de terror nos Estados Unidos, no início da década de 1950, quadrinistas brasileiros passaram a produzir esse tipo de material, que tinha grande apelo popular, para pequenas editoras localizadas em São Paulo (Outubro, Edrel, Taika e GEP, dentre outras). As histórias de terror em quadrinhos realizadas no Brasil não apresentam apenas arte de qualidade e roteiros estruturados, mas se diferenciam pelo conteúdo que privilegia elementos da cultura nacional e pelo erotismo. Fazem parte da mitologia brasileira superstições, narrativas e personagens (curupira, mula sem cabeça, entidades do candomblé etc.) assustadores. Essas histórias, com suas simpatias e seus tipos, são passadas de uma geração a outra, mesclando tradições nativas, europeias e oriundas da África. O interior, o sertão, é o lugar propício para sua criação e proliferação, uma vez que, além da vastidão e da desolação, predomina a cultura oral nesses lugares distantes dos centros urbanos. O ambiente da maior parte dos quadrinhos de terror produzidos no Brasil é, portanto, interiorano.

De acordo com Cirne (1990: 37), o quadrinho brasileiro de terror, "passando pelo folclore e pelo imaginário popular, poderá, assim, ser um gênero essencialmente brasileiro". Para o autor, personagens como Zé do Caixão e Chico de Ogum representam esta faceta popular carregada de brasilidade; ele acrescentou que as narrativas abordam, inclusive, questões políticas. Essas características estão presentes nas revistas produzidas pela Editora D-Arte ao longo da década de 1980.

Tudo começou quando o artista argentino Rodolfo Zalla fixou-se no Brasil, nos anos 1960, e criou o Estúdio DArte, que criava quadrinhos de terror, western e guerra. Para a realização dessas histórias, o estúdio contava com a colaboração do desenhista italiano Eugenio Colonnese, do roteirista Luis Meri Quevedo, além de diversos talentos brasileiros. No início da década de 1980, Zalla fundou a Editora D-Arte, e sua primeira publicação foi a revista de quadrinhos de western Johnny Pecos, lançada em 1981, e que teve apenas quatro edições. No mesmo ano, surgiu Calafrio, publicado até 1992. Outro periódico de quadri- nhos de terror da D-Arte foi Mestres do Terror, criado em 1987 e editado até 1993. Essas duas revistas reuniam os principais artistas em atividade no Brasil naquele momento, como Mozart Couto, Flavio Colin, Eugenio Colonnese e Luis Meri Quevedo, dentre outros.

Tabela 2: Publicações da Editora D-Arte

\begin{tabular}{lccc}
\hline Título & $\begin{array}{c}\text { Data } \\
\text { inicial }\end{array}$ & $\begin{array}{c}\text { Data } \\
\text { final }\end{array}$ & $\begin{array}{c}\text { Número } \\
\text { de edições }\end{array}$ \\
\hline Mestres do Terror & 1987 & 1993 & 57 \\
\hline Mestres do Terror Especial & & & 4 \\
\hline Calafrio & 1981 & 1992 & 48 \\
\hline Calafrio Especial & & 1992 & 4 \\
\hline Johnny Pecos & 1981 & 1982 & 4 \\
\hline Total de edições & & $\mathbf{1 1 7}$ & \\
\hline
\end{tabular}

Cirne (1990: 44) considerou que, "mais do que uma realidade editorial, o quadrinho de terror, em nosso país, é uma realidade cultural". São as referências à cultura brasileira que dão a tônica de várias histórias de terror realizadas por artistas nacionais. Essa característica pode ser constatada em diversas histórias publicadas nas revistas da Editora D-Arte. As simpatias e crenças populares, assim como uma das manifestações culturais mais características do Brasil, o Carnaval, se encontram em Superstições (com roteiro de Luis Meri Quevedo e arte de Colonnese), onde se acompanha um ladrão de túmulos que penetra no cemitério na véspera da festa, contrariando a superstição que adverte contra o mau agouro desta atitude.

Já em Cinderela da gafieira (escrita por Ota e desenhada por Mozart Couto), o ambiente é de outra manifestação cultural popular brasileira, a gafieira (salão de dança onde a noite é embalada ao ritmo do samba). Nesse lugar, uma bela morena desperta o interesse de um frequentador, que se espanta por ela sempre sair do baile antes da meianoite. $\mathrm{O}$ apaixonado descobre, para sua própria danação, tratar-se de uma morta-viva que tem permissão para sair do cemitério para dançar na gafieira, mas precisa retornar à cova na hora marcada. $E$ a denúncia da violência contra os oprimidos está presente em histórias como Lamento fúnebre e Navio negreiro (ambas publicadas na revista Calafrio), que têm como argumento a vingança perpetrada pelo escravo negro, após sua morte, contra os brancos que o fizeram sofrer.

\section{C) Editora VHD-Diffusion}

A terceira editora pesquisada, VHD-Diffusion, pertencia a Vincent Henry Ducarme e iniciou suas atividades em 1983. 


\section{A renovação das histórias em quadrinhos nas publicações alternativas brasileiras da década de 1980}

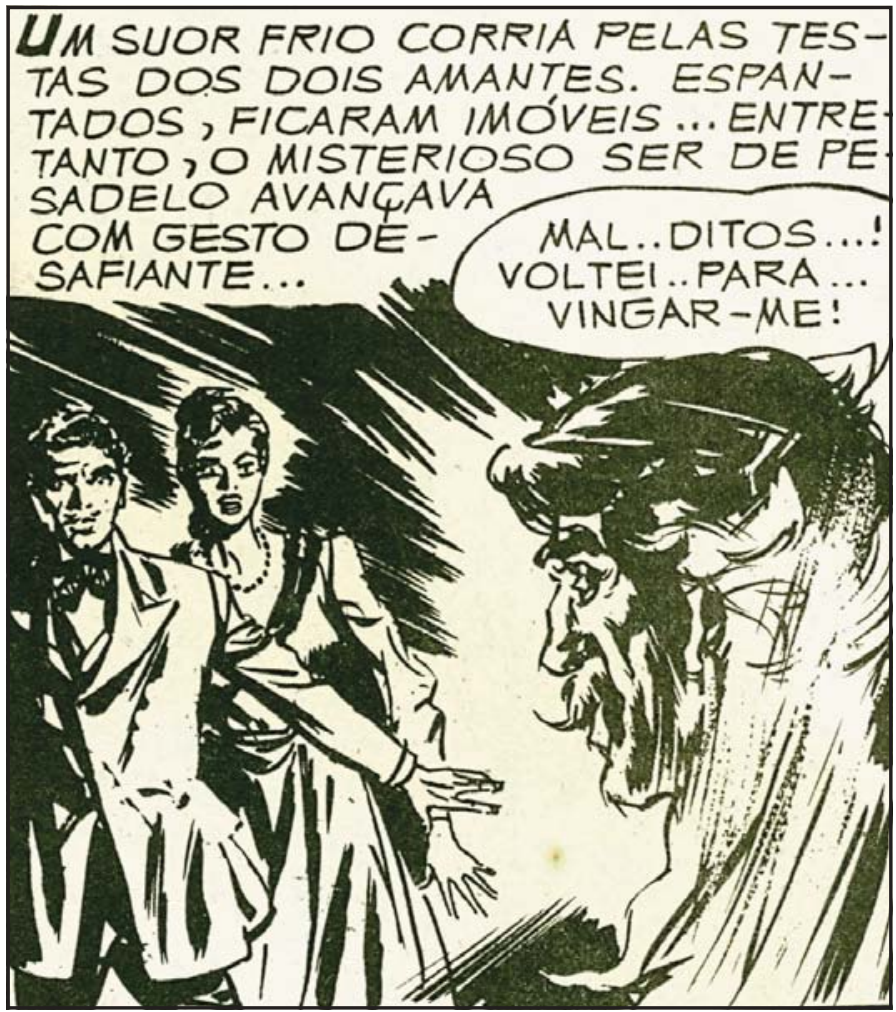

Figura 7: O terror na visão de Rodolfo Zalla

Inicialmente, essa casa publicadora colocou nas bancas álbuns de quadrinhos de aventura e western realizados por artistas europeus, como o bárbaro Thorgal (cujas histórias eram escritas pelo belga Jean Van Hamme e desenhadas pelo polonês Grzegorz Rosiñski) e Durango (criado pelo belga Yves Swolfes). Essas publicações, contudo, tiveram vida efêmera - quatro e três edições, respectivamente.

Mas, em 1988, o editor Rogério de Campos convenceu o proprietário da VHD a criar uma revista para apresentar aos leitores brasileiros o melhor do quadrinho de vanguarda europeu daquela época. Foi dessa forma que surgiu a revista Animal, que tinha o subtítulo Feio, forte e formal. Suas páginas traziam trabalhos de artistas alternativos italianos (Milo Manara, Tamburini e Liberatore, Massimo Mattioli, Andréa Pazienza e Magnus), espanhóis (Daniel Torres, Max, Jaime Martín), ingleses (Hunt Emerson, Jamie Hewlett e Alan Martin), norte-americanos (Jaime Hernandez, Peter Milligan e Brett Ewins) e brasileiros (André Toral, Priscila Farias, Osvaldo Pavanelli, Adão Iturrusgarai e Jaca).

Ao lado de Campos, que ocupava a função de editor da revista, também colaboravam os artistas Fabio Zimbres (editor de arte), Priscila Farias e Newton Foot, dentre outros. Cada edição oferecia ao público, além de histórias em quadrinhos, a seção Tam-Tam, com notícias e matérias sobre quadrinhos,

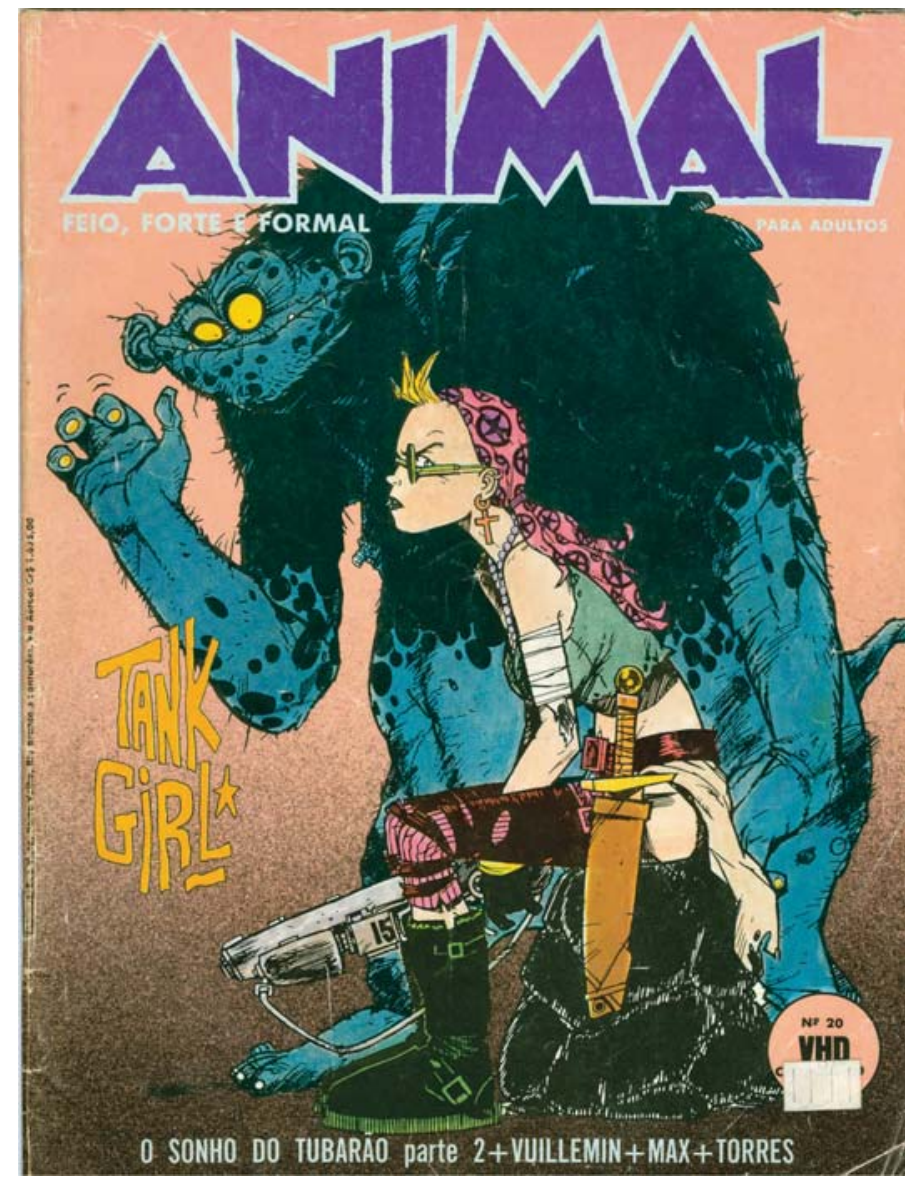

Figura 8: Capa da revista Animal: a estética punk de Tank Girl

e o encarte Mau (seu subtítulo, Feio, sujo e malvado, fazia alusão a um filme dirigido pelo cineasta italiano Ettore Scola). Similar a um fanzine, esse suplemento tratava de música e dava espaço para desenhos e tiras feitos pelos leitores e por artistas iniciantes ou consagrados, a exemplo de Hunt Emerson, Fernando Gonsales e Lourenço Mutarelli. Pela VHD, também saíram duas edições da Coleção Animal, de 1990 a 1996, e 15 edições da revista Níquel Náusea.

Tabela 3: Publicações da VHD-Diffusion

\begin{tabular}{lccc}
\hline Título & $\begin{array}{c}\text { Data } \\
\text { inicial }\end{array}$ & $\begin{array}{c}\text { Data } \\
\text { final }\end{array}$ & $\begin{array}{c}\text { Número } \\
\text { de edições }\end{array}$ \\
\hline Animal & 1988 & 1991 & 22 \\
\hline Coleção Animal & 1989 & 1989 & 2 \\
\hline Grandes Aventuras Animal & 1990 & 1991 & 8 \\
\hline Níquel Náusea & 1990 & 1996 & 15 \\
\hline Thorgal & 1983 & 1983 & 4 \\
\hline Durango & & & 3 \\
\hline Total de edições & & 54 & \\
\hline
\end{tabular}


A renovação das histórias em quadrinhos nas publicações alternativas brasileiras da década de $\mathbf{1 9 8 0}$

\section{Considerações finais}

Como demonstrado ao longo do texto, a produção editorial de publicações alternativas de quadrinhos no Brasil, durante a década de 1980, refletiu o contexto político, econômico e social da época, incorporando a seu conteúdo os dilemas, as ideias e as atitudes de seus contemporâneos, seja na forma de crítica visceral, seja de sátira. As histórias e os personagens demonstravam a aversão de seus criadores à forma como a política era conduzida e a uma sociedade cada vez mais materialista e voltada para o consumo.

Além disso, os quadrinhos realizados ou editados naquele momento promoveram inovações: seja em relação à narrativa (a fragmentação da ação e os múltiplos focos narrativos utilizados nas graphic novels), seja ao estilo gráfico o uso de hachuras que deixavam o desenho "sujo", a mis- tura de elementos visuais (fotografia, pintura, desenho), a estética retrô (presente na arquitetura dos cenários, no figurino e na fisionomia dos personagens) -, assim como ao uso de metalinguagem (cross-overs de personagens, citações).

No Brasil, essas revistas também revelaram novos quadrinistas que se consagraram nas décadas seguintes, a exemplo do gaúcho Adão Iturrusgarai e do paulista Lourenço Mutarelli. Dessa forma, é possível entendê-las como uma produção alternativa no sentido que, do ponto de vista artístico, renovaram a estético e o conteúdo dos quadrinhos; no que concerne à política, criticavam ou opunhamse aos ditames das classes dominantes e às normas estabelecidas; e, no que se refere ao mercado editorial, tornavam-se opções às publicações comerciais.

\section{Referências}

Bryan, Guilherme. Quem tem um sonho não dança: cultura jovem brasileira nos anos 80. Rio de Janeiro: Record, 2004.

CIRne, Moacy. História e crítica dos quadrinhos brasileiros. Rio de Janeiro: Europa/Funarte, 1990.

Connor, Steven. Cultura pós-moderna - introdução às teorias do contemporâneo. 2. ed. São Paulo: Loyola, 1993.

De SANtIS, Pablo. La historieta en la edad de la razón. Buenos Aires: Paidós, 2004.

Dopıco, Pablo. El cómic underground español, 1970-1980. Madrid: Cátedra, 2005.

HABERMAS, Jürgen. Modernidade versus pós-modernidade. Arte em Revista, ano 5, n. 7, São Paulo, agosto, 1983.

How, James. 2000AD and Hollywood: the special relationship between a British comic and American film. In: Magnussen, Anne \& Christiansen, Hans-Christian (eds.). Comics \& culture - analytical and theoretical approaches to comics. Copenhagen: Museum Tusculanum Press/ University of Copenhagen, 2000.

KelLner, Douglas. A cultura da mídia - estudos culturais: identidade e política entre o moderno e o pós-moderno. Bauru: Edusc, 2001.
LASCH, Christopher. O mínimo Eu: sobrevivência psíquica em tempos difíceis. São Paulo: Brasiliense, 1986.

Merino, Ana. El cómic hispânico. Madrid: Cátedra, 2003.

Mostaço, Edelcio. Alternativa: independência ou morte notas sobre o circuito da ideologia. Arte em Revista, ano 6, n. 8, São Paulo, outubro, 1984.

Nery, João Elias. Graúna e Rê Bordosa: o humor gráfico brasileiro de 1970 e 1980. São Paulo: Terras do Sonhar/ Pulsar, 2006.

Rosencrantz, Patrick. Rebel visions - the underground comix revolution, 1963-1975. Seattle: Fantragraphics Books, 2002.

ScolaRI, Carlos A. Historietas para sobrevivientes - comic y cultura de masas em los años 80. Buenos Aires: Colihue, 1999.

Silva, Nadilson M. da. Fantasias e cotidiano nas histórias em quadrinhos. São Paulo: Annablume, 2002.

WEINER, Stephen. Faster than a speeding bullet: The rise of the graphic novel. New York: Nantier-Beall-Minoustchine Publishing Inc., 2003.

Wolk, Douglas. Reading comics: how graphic novels work and what they mean. Cambridge: Da Capo Press, 2007. 